\title{
Magnetic and electrical stimulation of cervical motor roots: technique, site and mechanisms of excitation
}

\author{
U D Schmid, G Walker, C W Hess, J Schmid
}

\begin{abstract}
Cervical motor roots and the brachial plexus were excited transcutaneously with magnetic (MagStim) and electrical stimulation (E1Stim) applied dorsally over the spine and over the supraclavicular fossa (Erb's point). The compound muscle action potentials (CMAPs) from the abductor digiti minimi (ADM) and the biceps muscles (BICEPS) could be evoked with either stimulating technique in all 52 subjects tested. With MagStim over the spinous process C7, greater CMAPs were obtained from ADM ( $1 \leqslant 0.0001$, paired $t$ test) and BICEPS (p $\leqslant 0.005)$ when the inducing current in the coil as viewed from behind was clockwise for the right arm and vice versa. ElStim with the cathode over $\mathrm{C} 7 / \mathrm{T} 1$ and the anode directed cranially provided greater CMAPs from the ADM ( $\leqslant \leqslant 0.0001)$ and smaller CMAPs from the BICEPS $(p \leqslant 0.01)$ than with the inverse polarity. MagStim of the cervical roots provided CMAPs which were smaller from $A D M(p \leqslant$ $0.0001)$, and greater from BICEPS ( $p \leqslant$ 0.0001), than ElStim (cathode C7/T1), whereas latencies did not differ significantly $(p \leqslant 0.3)$. When comparing E1Stim and MagStim applied over Erb's point, the former yielded greater CMAPs and $0.5 \mathrm{~ms}$ longer latencies from both the ADM and BICEPS ( $p \leqslant 0.0001$ ). From these data and additional studies in four patients, including direct intraoperative root stimulation in one of them, it is concluded that EIStim and MagStim over the spine excite the motor roots at a similar site, that is, within a few cm outside the intervertebral foramina. The site of stimulation is difficult to predict and depends on the placement of the stimulating devices and the intensities used. In contrast, MagStim of the brachial plexus over Erb's point occurs on average about $3.5 \mathrm{~cm}$ distal to the site of E1Stim.
\end{abstract}

By applying high voltage low output impedance electrical stimuli over the back of the lower cervical column, responses in upper limb muscles are easily evoked, ${ }^{1-5}$ and the elicited compound muscle action potentials (CMAPs) are similar to those following distal nerve stimulation. With this method axons of the motor roots rather than neural elements within the spinal cord are excited, and excitation takes place near the exit intervertebral foramina. ${ }^{3}$ Using stimulation with a rapidly time varying magnetic field, a technique now adopted for painless non-invasive stimulation of the human motor cortex, ${ }^{67}$ CMAPs from upper limb muscles can also be obtained when the stimulating coil is placed over the cervical column, ${ }^{8-11}$ or over the peripheral nerves of limbs. ${ }^{1012-14}$ The methods of cervical root stimulation obviously open a new perspective in electroneurography, enabling the assessment of the proximal segment of the brachial plexus. Proximal conduction block in patients with Guillain-Barré syndrome has been shown using the electrical cervical root stimulation method. ${ }^{1516}$ Furthermore, stimulation of the cervical motor roots is used for assessing central motor conduction time (CMCT) by motor cortex stimulation, where the peripheral nerve conduction time (PNCT) must be subtracted from the total latency of the responses. However, various techniques of electrical and magnetic root stimulation are used and the differences of reported CMCT and PNCT may, in part, reflect methodological dissimilarities of stimulating. technique. ${ }^{17}$

In this study we aimed to compare and optimise the techniques of both electrical and magnetic cervical root stimulation when recording from the $\mathrm{ADM}$ and BICEPS. Special attention was given to the questions of whether and how stimulation could be confined to the most proximal segment of the motor roots.

\section{Methods}

Subjects

The experiments complied with the standards of the local ethical committee, and subjects gave their informed consent. Forty eight healthy subjects ( 28 males and 20 females, mean age $28 \cdot 21$, age range from 23-39 years) and four male patients (22-62 years) with acute brachial neuralgias volunteered for the experiments.

\section{Stimulation and recording technique}

Transcutaneous stimulation was carried out in a sitting position, the vertebra prominens $\mathrm{C7}$ serving as a landmark for the positioning of the stimulating devices over the neck. The brachial plexus was stimulated over the supraclavicular fossa at Erb's point.

Electrical stimuli were delivered by a low output impedance stimulator (Digitimer D 
180); the stimulation intensities used were expressed as a percentage of the maximal peak output voltage of $750 \mathrm{~V}$. As a result of a previous study, ${ }^{5}$ stimulation over the neck was performed with longitudinal rather than transverse electrode placement, at an interelectrode distance of $6 \mathrm{~cm}$, and an area of skin contact of $1.0 \mathrm{~cm}^{2}$. Either the cathode or the anode was placed over the $\mathrm{C} 7 / \mathrm{T} 1$ interspinous space. An interelectrode distance of $2 \mathrm{~cm}$ and area of skin contact of $0.5 \mathrm{~cm}^{2}$ were used for peripheral nerve stimulation at the wrist, in the axilla and at Erb's point.

Magnetic stimulation was performed with stimulating coils composed of 17 concentric circular turns of copper wire through which a brief current pulse of a capacitive discharge was passed. The magnetic stimulator had a total capacitance of $800 \mu \mathrm{F}$ with a maximum charging energy of 2500 Joules. For comparison, two different coils with a mean diameter of $8 \mathrm{~cm}$ or $6 \mathrm{~cm}$ with a resistance of 14 or 12 $\mathrm{m} \Omega$ and an inductance of 32 or $22 \mu \mathrm{H}$ respectively were used. To facilitate the positioning of the coils around a spinous process, they were built with a narrow winding and relatively ample inner space of 6 and $4 \mathrm{~cm}$ mean diameter. At a capacitor discharge of $2.5 \mathrm{kV}$, the peak magnetic field was 2.3 Tesla in the centre of the coil, with a rise time of $115 \mu \mathrm{s}$ and a virtually exponential decay. The stimulation intensities used were expressed as a percentage of the maximum peak output voltage of $2.5 \mathrm{kV}$.

Muscle responses were recorded with surface electrodes taped over the belly and tendon of the ADM and BICEPS of both arms. During cervical stimulation, responses of the four muscles were recorded simultaneously on a 4-channel recording unit (Medelec ER 94a), interfaced to a microcomputer for digital storage and off-line evaluation. The bandpass of amplifiers was $1 \mathrm{~Hz}$ and $6 \mathrm{kHz}$.

Onset latencies of the CMAP were measured at the first sharp negative potential deflection from the baseline. ${ }^{5}$ Amplitudes were determined between the baseline and the negative maximum. The distances were measured on the sideways extended arms between the spinous process $\mathrm{C} 7$ and the peripheral stimulation points of the arm and at Erb's point. The values were statistically analysed with the two-tailed paired $t$ test.

\section{Experimental procedures with electrical stimulation}

To study the effect of electrical stimulus intensity (three subjects, four experiments), the stimulation electrodes were positioned longitudinally with the cathode at the C7/T1 interspinous space and the anode $6 \mathrm{~cm}$ cranially. The stimulus intensity was raised stepwise from $10-100 \%$.

In 11 experiments (22 sides), different electrode polarities were compared. The cathode was placed at the $\mathrm{C} 7 / \mathrm{T} 1$ interspinous space with the anode directed $6 \mathrm{~cm}$ cranially in the midline $(\mathrm{C} 7 / \mathrm{T} 1(-))$, and subsequently the polarity was reversed $(\mathrm{C} 7 / \mathrm{T} 1(+))$. Stimulus intensities were adjusted to obtain just maximal amplitudes of the CMAPs from ADM and BICEPS on both sides (see below).

\section{Experimental procedures with magnetic} stimulation

In a first series of experiments ( 12 subjects, 21 experiments), the effects of diameter of the magnetic coil $(6$ or $8 \mathrm{~cm})$, of the orientation of the inducing current (clockwise or anticlockwise), and the effect of stimulus intensity were studied. Furthermore, positions of the magnetic coil over Erb's point, $8 \mathrm{~cm}$ paramedian to the spinous process $\mathrm{C} 7$ over the crest of the transverse part of the trapezius muscle, and in the midline over the spinous processes $\mathrm{C} 3$, C5, C6, C7, and T1 were compared.

In a second series of experiments (22 subjects, 44 sides), magnetic stimuli were

Table 1 Latencies and side-to-side differences [mean (1 SD)] of CMAPs from ADM and BICEPS

\begin{tabular}{|c|c|c|c|c|c|c|c|}
\hline & & \multicolumn{2}{|c|}{ Right side } & \multicolumn{2}{|c|}{ Left side } & \multicolumn{2}{|c|}{$\begin{array}{l}\text { Side-to-side } \\
\text { difference }\end{array}$} \\
\hline & & Mean & $(S D)$ & Mean & $(S D)$ & Mean & $(S D)$ \\
\hline \multicolumn{8}{|c|}{ Electrical stimulation $\dagger(\mathrm{n}=22$ subjects $)$} \\
\hline & C7-BICEPS & 5.1 & $(0.7)$ & 5.2 & $\left.\begin{array}{l}(1.8) \\
(0.6)\end{array}\right)$ & $\begin{array}{l}0.3 \\
0.3\end{array}$ & $\begin{array}{l}(0.4) \\
(0.4)\end{array}$ \\
\hline & Erb-ADM & $12 \cdot 8$ & $(1 \cdot 6)$ & $12 \cdot 6$ & $(1 \cdot 6)$ & 0.3 & $(0 \cdot 4)$ \\
\hline Conduction time (ms) & Erb-BICEPS & $4 \cdot 1$ & $(0 \cdot 6)$ & $4 \cdot 0$ & $(0.5)$ & $0 \cdot 3$ & $(0.4)$ \\
\hline Conduction time (mins) & $\begin{array}{l}\text { C7-axilla (N. Uln.) } \\
\text { C7-axilla (N. M'cut`) }\end{array}$ & $\begin{array}{l}4 \cdot 3 \\
3 \cdot 1\end{array}$ & $\begin{array}{l}(0.8) \\
(0.8)\end{array}$ & $\begin{array}{l}4 \cdot 1 \\
3 \cdot 2\end{array}$ & $(0.6)$ & $\begin{array}{l}0.3 \\
0.6\end{array}$ & $(0.5)$ \\
\hline Conduction velocity $(\mathrm{m} / \mathrm{s})$ & $\begin{array}{l}\text { C7-axilla (N. Uln.) } \\
\text { C7-wrist (N. Uln.) }\end{array}$ & $\begin{array}{l}71 \cdot 3 \\
63 \cdot 3\end{array}$ & $\begin{array}{l}(7.7) \\
(3.6)\end{array}$ & $\begin{array}{l}72 \cdot 8 \\
64 \cdot 3\end{array}$ & $\begin{array}{l}(7.9) \\
(4 \cdot 6)\end{array}$ & $\begin{array}{l}5 \cdot 2 \\
2 \cdot 2\end{array}$ & $\begin{array}{l}(6 \cdot 3) \\
(2 \cdot 5)\end{array}$ \\
\hline & C7-axilla (N. M'cut) & $84 \cdot 3$ & (13.7) & $80 \cdot 2$ & $(10 \cdot 4)$ & $12 \cdot 3$ & $(14 \cdot 7)$ \\
\hline \multicolumn{8}{|c|}{ Magnetic stimulation $+\dagger$ ( $n=22$ subjec } \\
\hline Latency (ms) & $\begin{array}{l}\text { C7-ADM } \\
\text { C7-BICEPS }\end{array}$ & $\begin{array}{r}13 \cdot 9 \\
5 \cdot 2\end{array}$ & $(1.8)$ & $\begin{array}{r}13.5 \\
5.3\end{array}$ & $\begin{array}{l}(1 \cdot 8) \\
(0 \cdot 6)\end{array}$ & $\begin{array}{l}0.6 \\
0.3\end{array}$ & $(0.6)$ \\
\hline & Erb-ADM & $12 \cdot 3$ & (1.6) & $12 \cdot 1$ & $(1.7)$ & $\begin{array}{l}0.3 \\
0.5\end{array}$ & $\begin{array}{l}(0.4) \\
(0.6)\end{array}$ \\
\hline Conduction time (ms) & Erb-BICEPS & 3.6 & $(0 \cdot 6)$ & 3.5 & $(0.5)$ & 0.3 & $(0.5)$ \\
\hline 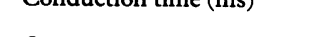 & C7-axilla (N. Uln.) & $\begin{array}{l}4 \cdot 3 \\
3 \cdot 2\end{array}-x-10$ & $(0.7)$ & $\begin{array}{r}3.9 \\
3.3\end{array}$ & $(0 \cdot 6)$ & 0.5 & $(0.5)$ \\
\hline Conduction velocity $(\mathrm{m} / \mathrm{s})$ & C7-axilla (N. Uln.) & 70.7 & $(9 \cdot 1)$ & $76 \cdot 6$ & $(10 \cdot 1)$ & $\begin{array}{l}0.3 \\
8.7\end{array}$ & $\begin{array}{l}(0.6) \\
(8 \cdot 5)\end{array}$ \\
\hline & C7-wrist (N. Uln.) & $63 \cdot 0$ & $(4 \cdot 0)$ & $65 \cdot 4$ & $(5 \cdot 1)$ & $3 \cdot 1$ & $(2 \cdot 9)$ \\
\hline & C7-axilla (N. M'cut) & $83 \cdot 4$ & (13.6) & $78 \cdot 0$ & $(9 \cdot 7)$ & $11 \cdot 3$ & (13.7) \\
\hline
\end{tabular}

*N. M(usculo)cut(aneous).

†Cervical stimulation was done with longitudinal electrical stimulation (cathode C7/T1, anode $6 \mathrm{~cm}$ cranially), and with magnetic stimulation (coil centred at C7, clockwise flow of inducing current as viewed from behind for the right side, and vice versa). t+Plexus stimulation over Erb's point (see text). 
Table 2 Amplitudes of CMAPs from ADM and BICEPS muscles ( $\mathrm{mV}$, mean and range

\begin{tabular}{|c|c|c|c|c|c|c|}
\hline & \multicolumn{2}{|c|}{ Right side } & \multicolumn{2}{|c|}{ Left side } & \multicolumn{2}{|c|}{$\begin{array}{l}\text { Side-to-side } \\
\text { difference }\end{array}$} \\
\hline & Mean & Range & Mean & Range & Mean & Range \\
\hline $\begin{array}{l}\text { Electrical stim } \\
\text { C7-ADM } \\
\text { C7-BICEPS } \\
\text { Erb-ADM } \\
\text { Erb-BICEPS }\end{array}$ & $\begin{array}{c}(\mathrm{n}=2 \\
8 \cdot 0 \\
7 \cdot 0 \\
8 \cdot 5 \\
11 \cdot 3\end{array}$ & $\begin{array}{l}\text { subjects) } \\
1 \cdot 4-12 \cdot 0 \\
1 \cdot 4-14 \cdot 0 \\
2 \cdot 3-12 \cdot 6 \\
6 \cdot 8-17 \cdot 0\end{array}$ & $\begin{array}{l}8 \cdot 4 \\
6 \cdot 1 \\
9 \cdot 0 \\
9 \cdot 8\end{array}$ & $\begin{array}{l}3 \cdot 4-11 \cdot 9 \\
0 \cdot 7-12 \cdot 2 \\
3 \cdot 1-12 \cdot 3 \\
6 \cdot 5-13 \cdot 0\end{array}$ & $\begin{array}{l}1 \cdot 1 \\
1.9 \\
1 \cdot 2 \\
2 \cdot 1\end{array}$ & $\begin{array}{lr}0 & -3 \cdot 9 \\
0 \cdot 2-5 \cdot 2 \\
0 & -5 \cdot 3 \\
0 & -7 \cdot 5\end{array}$ \\
\hline $\begin{array}{l}\text { Magnetic stimu } \\
\text { C7-ADM } \\
\text { C7-BICEPS } \\
\text { Erb-ADM } \\
\text { Erb-BICEPS }\end{array}$ & $\begin{array}{c}\dagger(\mathrm{n}=2 \\
5 \cdot 1 \\
9 \cdot 1 \\
7 \cdot 6 \\
10 \cdot 6\end{array}$ & $\begin{array}{c}2 \text { subjects) } \\
1 \cdot 1-9 \cdot 8 \\
4 \cdot 9-13 \cdot 5 \\
2 \cdot 0-11 \cdot 0 \\
6 \cdot 4-14 \cdot 4\end{array}$ & $\begin{array}{l}5 \cdot 6 \\
7 \cdot 8 \\
8 \cdot 0 \\
9 \cdot 3\end{array}$ & $\begin{array}{l}1 \cdot 9-10 \cdot 2 \\
3 \cdot 5-12 \cdot 2 \\
3 \cdot 3-11 \cdot 2 \\
6 \cdot 4-12 \cdot 7\end{array}$ & $\begin{array}{l}1 \cdot 4 \\
2 \cdot 1 \\
1 \cdot 8 \\
1.9\end{array}$ & $\begin{array}{l}0-4 \cdot 8 \\
0 \cdot 1-5 \cdot 6 \\
0-5 \cdot 7 \\
0 \cdot 1-5 \cdot 1\end{array}$ \\
\hline
\end{tabular}

Cervical stimulation was done with longitudinal electrical stimulation $\dagger$ (cathode $\mathrm{C} 7 / \mathrm{T} 1$, anode $6 \mathrm{~cm}$ cranially), and with magnetic stimulation $+\dagger$ (coil centred at $\mathrm{C} 7$, clockwise flow of inducing current as viewed from behind for the right side, and vice versa).

$t+$ Plexus stimulation at Erb's point (see text).

delivered with the coil of $8 \mathrm{~cm}$ diameter centred over C7, and over Erb's point. Stimulus intensities for C7 stimulation were increased stepwise until latencies remained nearly stable (see below), and a clockwise and anticlockwise sense of the inducing current as viewed from behind was used. For stimulation over Erb's point, the inducing current was anticlockwise for the right arm and vice versa, and stimulus intensities were supramaximal as defined according to amplitudes.

The results after magnetic stimulation were then compared with those after electrical stimulation (22 subjects, 44 sides) over the spine and Erb's point.

\section{Patient studies}

Transcutaneous stimulation was performed as described, recordings from ADM or BICEPS or both were made and the results were compared to those obtained in normal groups (tables 1 and 2).

Case 1 had disc herniation C7/T1 with compressed left C8 root (CT), a sensorymotor radiculopathy $\mathrm{C} 8$ with weak small hand muscles, and abolished triceps and finger flexor reflexes.

Case 2 had disc herniation $\mathrm{C} 5 / 6$ with compressed left C6 root (myelogram/CT), a sensory-motor radiculopathy $\mathrm{C} 6$ with weak biceps muscle and abolished biceps tendon reflex.

Case 3 had disc herniation C6/7 with compressed left C7 root (myelogram/CT), a sensory-motor radiculopathy with weak triceps muscle and abolished triceps tendon reflex, but normal strength of the recorded BICEPS and ADM. After anterior discectomy, the left dural sleeve $\mathrm{C} 7$, exposed for about $7 \mathrm{~mm}$, was stimulated within the intervertebral foramen with a bipolar stimulation forceps.

Case 4 had traumatic incomplete left plexus paresis with weak triceps, deltoideus, biceps, and ADM muscles. Sensory testing in the left arm was normal.

\section{Results}

It proved easy to evoke CMAPs in ADM and BICEPS with both electrical and magnetic stimulation over the neck in both normal
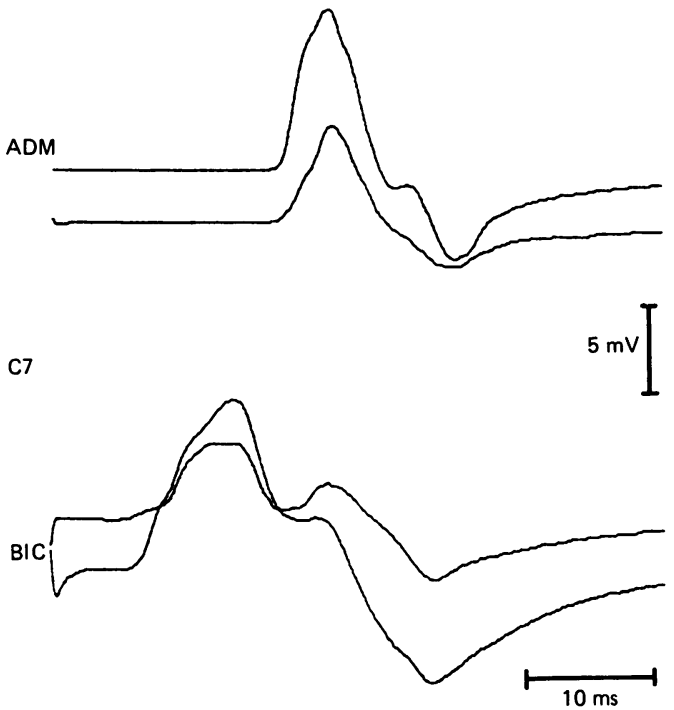

Figure 1 CMAPs from ADM and BICEPS following cervical root stimulation. Electrical stimulation (upper trace) : cathode $C 7 / T 1$, anode $6 \mathrm{~cm}$ cranially in the midline. Magnetic stimulation (lower trace): coil of $8 \mathrm{~cm}$ diameter over $C 7$.

subjects and patients, and the CMAPs had a general shape similar to the shape of those obtained from plexus stimulation at Erb's point (figs 1 and 2).

The sensation reported by the subjects during the electrical shock over the neck was a blunt jolt, probably due to contraction of the neck muscles, and also sometimes an involuntary short inspiration due to activation of the diaphragm. Following magnetic stimulation, the sensation in the neck was slightly weaker, and noticeable activation of the diaphragm did not occur. A concomitant muscle excitation in the lower limbs rarely occurred when strong electrical stimuli of up to $750 \mathrm{~V}$ were used, and this was not noticed after magnetic stimulation. When stimulating at Erb's point, subjects felt considerable discomfort during electrode placement and electrical stimulation, while stimulation with the magnetic coil was well tolerated.
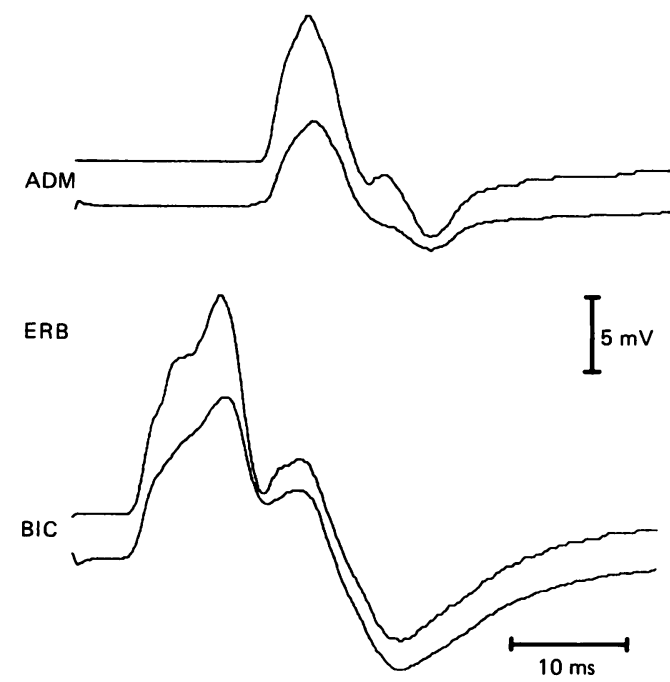

Figure 2 CMAPs from ADM and BICEPS following plexus stimulation over Erb's point in the same subject and side as fig 1. Electrical stimulation (upper trace); magnetic stimulation (lower trace). 
Figure 3 Amplitudes and latencies of CMAPs from $A D M$ (triangles) and BICEPS (rectangles) of the right (filled symbols) and left arm (empty symbols) following electrical cervical root stimulation using increasing stimulus intensities. Cathode $C 7$ $T 1$, anode $6 \mathrm{~cm}$ cranially in the midline (one subject, one trial/intensity).
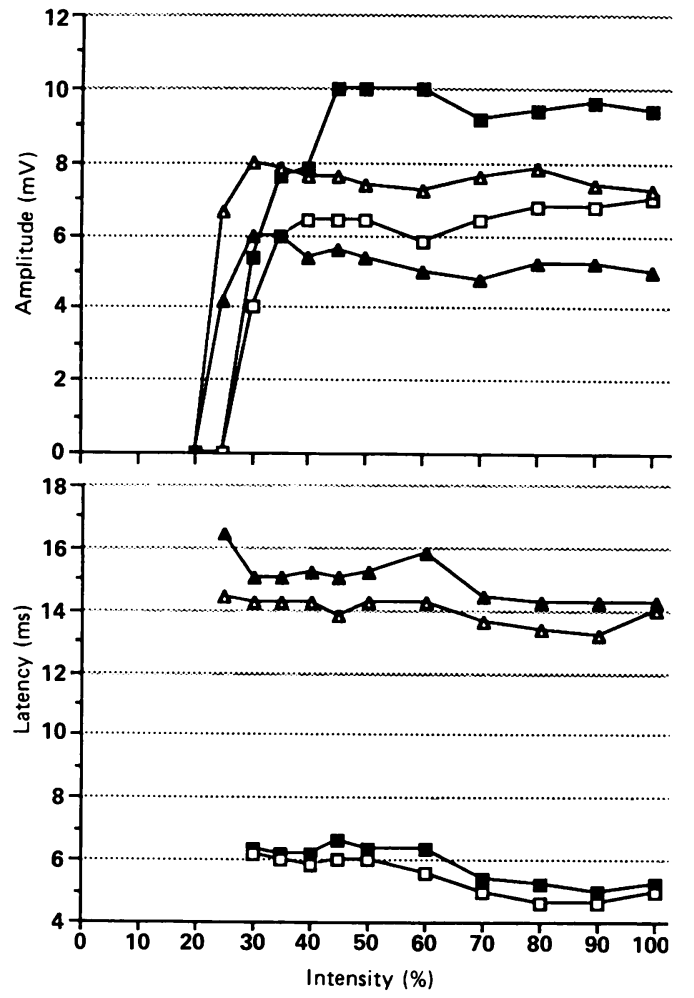

ELECTRICAL STIMULATION OF CERVICAL MOTOR ROOTS

Effects of electrical stimulus intensity (fig 3). Increasing stimulus intensities in the lower range caused a steady increase of the amplitudes of the CMAPs bilaterally. When the intensity was raised above 40 to $50 \%$, amplitudes saturated, whereas onset latencies remained stable only over a small range of stimulus intensities, and tended to shorten by up to $2 \mathrm{~ms}$ when the stimuli were raised still more by $20-30 \%$.

Effect of electrode polarity and placement (table 3). Regardless of the stimulus polarity, the electrical impulses elicited simultaneous responses on both sides from the ADM and
BICEPS in all subjects. With a stimulation intensity sufficient to obtain just maximal amplitudes of CMAPs, the cathode over C7/T1 and anode cranially provided on the average greater amplitudes in the ADM by $3 \mathrm{mV}$ ( $\mathrm{p} \leqslant$ 0.0001 ), and smaller amplitudes in the BICEPS by $2.1 \mathrm{mV}(\mathrm{p} \leqslant 0.01)$, than with the polarity reversed. The latencies of the responses tended to be shorter in the ADM $(0.17 \mathrm{~ms}$, $\mathrm{p} \leqslant 0.5)$ and BICEPS $(0.6 \mathrm{~ms}, \mathrm{p} \leqslant 0.02)$ when the cathode was over $\mathrm{C} 7 / \mathrm{T} 1$.

\section{MAGNETIC STIMULATION OF CERVICAL MOTOR ROOTS}

Effects of diameter and placement of the magnetic coil. When the $8 \mathrm{~cm}$ coil was centred over the spinous process $\mathrm{C} 7$, the amplitudes of $\mathrm{ADM}$ and BICEPS responses were consistently greater and latencies were longer by up to $0.6 \mathrm{~ms}$ than with either a paramedian position, or placement over Erb's point. Stimulation with the smaller $6 \mathrm{~cm}$ coil produced similar results with a paramedian or Erb's point position, but yielded clearly smaller responses when centred over the spinous process C7. When the $8 \mathrm{~cm}$ coil was moved along the midline over the spinous processes, the responses from the BICEPS were greatest with the coil centred over $\mathrm{C} 7$ (fig 4 , bottom). The position of the coil was less critical for the responses from the ADM, where the amplitudes with coil's centre over C5 tended to be greater than those from $\mathrm{C} 6$ and $\mathrm{C} 7$ stimulation and were variable from $\mathrm{T} 1$ stimulation (fig 4 , top). With the coil centred over T2 (to make the upper horizontal segment overlie C7 level) unambiguous responses from the ADM but not BICEPS were obtained, albeit clearly smaller than from $\mathrm{C} 7$ placement, and on one side only with the inverse current (see below). When comparing stimulation over $\mathrm{C} 3$ and $\mathrm{C} 7$, the former yielded smaller responses in the ADM, on the average by $3.8 \mathrm{mV}$ ( $\mathrm{n}=6$ subjects, 12 sides, $\mathrm{p} \leqslant 0.005)$, with a tendency to longer

Table 3 Comparison of various methods for electrical and magnetic stimulation over C7 and recording from BICEPS and $A D M$ ( $p$-value of the paired $t$ test)

\begin{tabular}{|c|c|c|c|c|c|c|c|c|}
\hline \multicolumn{4}{|c|}{ Stimulation and recording } & \multirow{2}{*}{\multicolumn{4}{|c|}{$\frac{\text { Difference of the mean values, pooled data }(S E)}{A \text { minus } B}$}} & \multirow[b]{3}{*}{$\begin{array}{l}\text { Subjec } \\
\text { sides }\end{array}$} \\
\hline \multicolumn{2}{|l|}{$A$} & \multicolumn{2}{|l|}{$B$} & & & & & \\
\hline Stimulation & Recording & Stimulation & Recording & $\begin{array}{l}\text { Latency } \\
\text { (ms) }\end{array}$ & p-value & $\begin{array}{l}\text { Amplitudes } \\
(m V)\end{array}$ & p-value & \\
\hline $\begin{array}{l}\text { Electrical } \\
\text { Cathode } \\
\text { C7/T1 }\end{array}$ & $\begin{array}{l}\text { BICEPS } \\
\text { Right } \\
\text { Left }\end{array}$ & $\begin{array}{l}\text { Electrical } \\
\text { Anode } \\
\text { C7/T1 }\end{array}$ & $\begin{array}{l}\text { BICEPS } \\
\text { Right } \\
\text { Left }\end{array}$ & $\begin{array}{c}-0.60 \\
(0.23)\end{array}$ & $\leqslant 0.02$ & $\begin{array}{c}-2 \cdot 12 \\
(0.75)\end{array}$ & $\leqslant 0.01$ & $11 / 22$ \\
\hline $\begin{array}{l}\text { Magnetic } \\
\text { Anticlockwise } \\
\text { Clockwise }\end{array}$ & $\begin{array}{l}\text { BICEPS } \\
\text { Right } \\
\text { Left }\end{array}$ & $\begin{array}{l}\text { Magnetic } \\
\text { Clockwise } \\
\text { Anticlockwise }\end{array}$ & $\begin{array}{l}\text { BICEPS } \\
\text { Right } \\
\text { Left }\end{array}$ & $\begin{array}{r}+0.22 \\
(0.04)\end{array}$ & $\leqslant 0.0001$ & $\begin{array}{c}-0.95 \\
(0.31)\end{array}$ & $\leqslant 0.005$ & $22 / 44$ \\
\hline $\begin{array}{l}\text { Electrical } \\
\text { Cathode } \\
\text { C } 7 / \mathrm{T} 1\end{array}$ & $\begin{array}{l}\text { BICEPS } \\
\text { Right } \\
\text { Left }\end{array}$ & $\begin{array}{l}\text { Magnetic } \\
\text { Clockwise } \\
\text { Anticlockwise }\end{array}$ & $\begin{array}{l}\text { BICEPS } \\
\text { Right } \\
\text { Left }\end{array}$ & $\begin{array}{c}-0.07 \\
(0.05)\end{array}$ & $\leqslant 0 \cdot 3$ & $\begin{array}{c}-1.87 \\
(0.46)\end{array}$ & $\leqslant 0.0001$ & $22 / 44$ \\
\hline $\begin{array}{l}\text { Electrical } \\
\text { Cathode } \\
\text { C } 7 / T 1\end{array}$ & $\begin{array}{l}\text { ADM } \\
\text { Right } \\
\text { Left }\end{array}$ & $\begin{array}{l}\text { Electrical } \\
\text { Anode } \\
\mathrm{C} 7 / \mathrm{T} 1\end{array}$ & $\begin{array}{l}\text { ADM } \\
\text { Right } \\
\text { Left }\end{array}$ & $\begin{array}{c}-0 \cdot 17 \\
(0 \cdot 16)\end{array}$ & $\leqslant 0.5$ & $\begin{array}{r}+2.97 \\
(0.50)\end{array}$ & $\leqslant 0.0001$ & $11 / 21$ \\
\hline $\begin{array}{l}\text { Magnetic } \\
\text { Anticlockwise } \\
\text { Clockwise }\end{array}$ & $\begin{array}{l}\text { ADM } \\
\text { Right } \\
\text { Left }\end{array}$ & $\begin{array}{l}\text { Magnetic } \\
\text { Clockwise } \\
\text { Anticlockwise }\end{array}$ & $\begin{array}{l}\text { ADM } \\
\text { Right } \\
\text { Left }\end{array}$ & $\begin{array}{c}-0.09 \\
(0.07)\end{array}$ & $\leqslant 0.3$ & $\begin{array}{c}-3 \cdot 81 \\
(0 \cdot 33)\end{array}$ & $\leqslant 0.0001$ & $22 / 44$ \\
\hline $\begin{array}{l}\text { Electrical } \\
\text { Cathode } \\
\text { C7/T1 }\end{array}$ & $\begin{array}{l}\text { ADM } \\
\text { Right } \\
\text { Left }\end{array}$ & $\begin{array}{l}\text { Magnetic } \\
\text { Clockwise } \\
\text { Anticlockwise }\end{array}$ & $\begin{array}{l}\text { ADM } \\
\text { Right } \\
\text { Left }\end{array}$ & $\begin{array}{c}+0.07 \\
(0.07)\end{array}$ & $\leqslant 0.3$ & $\begin{array}{c}+2.89 \\
(0.35)\end{array}$ & $\leqslant 0.0001$ & $22 / 44$ \\
\hline
\end{tabular}


Figure 4 Amplitudes of $C M A P$ s from the left $A D M$ (top) and BICEPS (bottom) following anticlockwise magnetic stimulation with the coil centred over $C 5$, C6, C7 or T1. Coil diameter was $8 \mathrm{~cm}$ stimulus intensity $90 \%$. Individual (symbols) and mean values (solid line) in three subjects (three trials) stimulus site/subject).
Figure 5 Amplitudes and latencies of CMAPs from the left ADM (triangles) and BICEPS (rectangles) following anticlockwise (black symbols) and clockwise (empty symbols) magnetic stimulation over $C 7$ and increasing intensities (one trial) intensity/current flow).
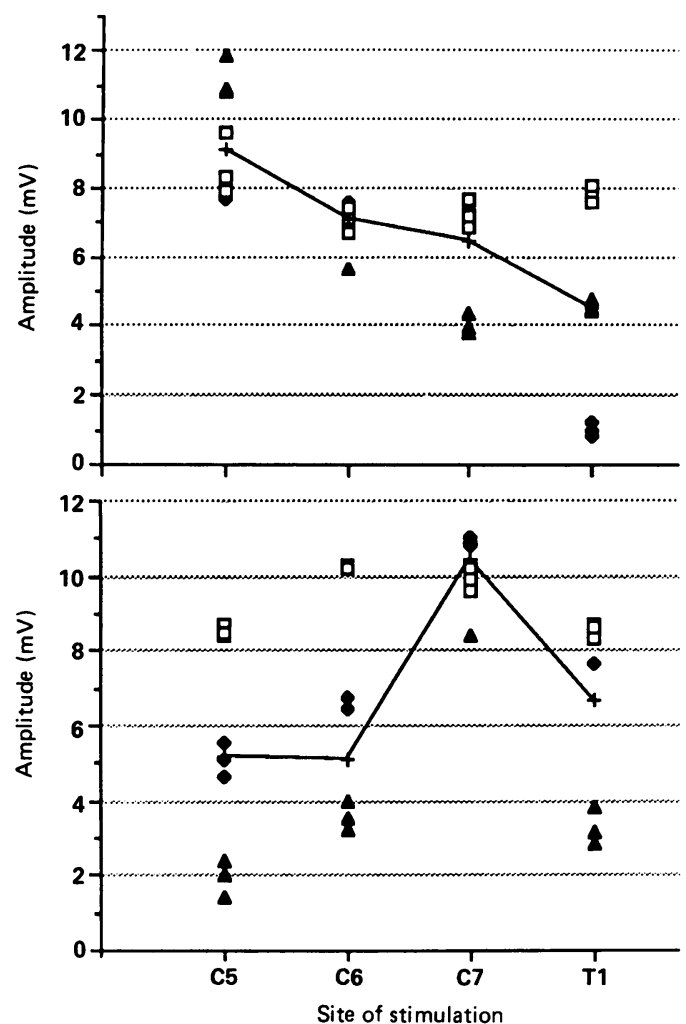

latencies (difference: $0.32 \mathrm{~ms}, 0.5>\mathrm{p}>0.1$ ). Hence, the coil of $8 \mathrm{~cm}$ diameter centred over C7 was used for subsequent experiments.

Influence of the sense of inducing current. With the coil centred over C7, the muscles of the left arm were more easily activated and yielded significantly greater amplitudes of CMAPs when the inducing current flowed anticlockwise as viewed from behind, and vice versa. This was particularly true for the ADM, and less pronounced for the BICEPS (figs 5 and 8, table 3). Anticlockwise current provided
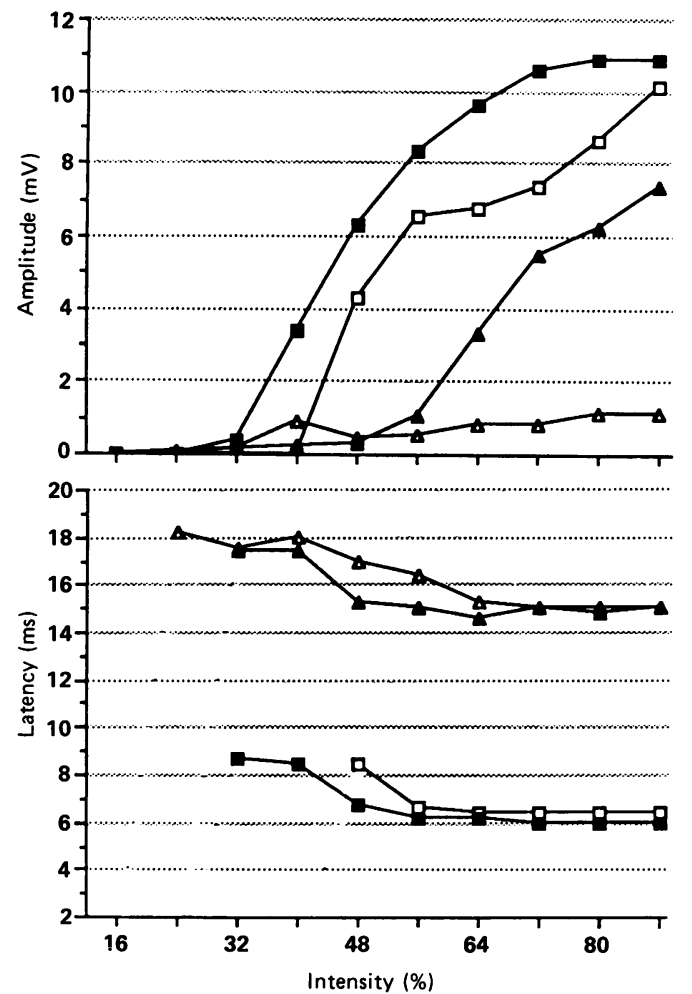

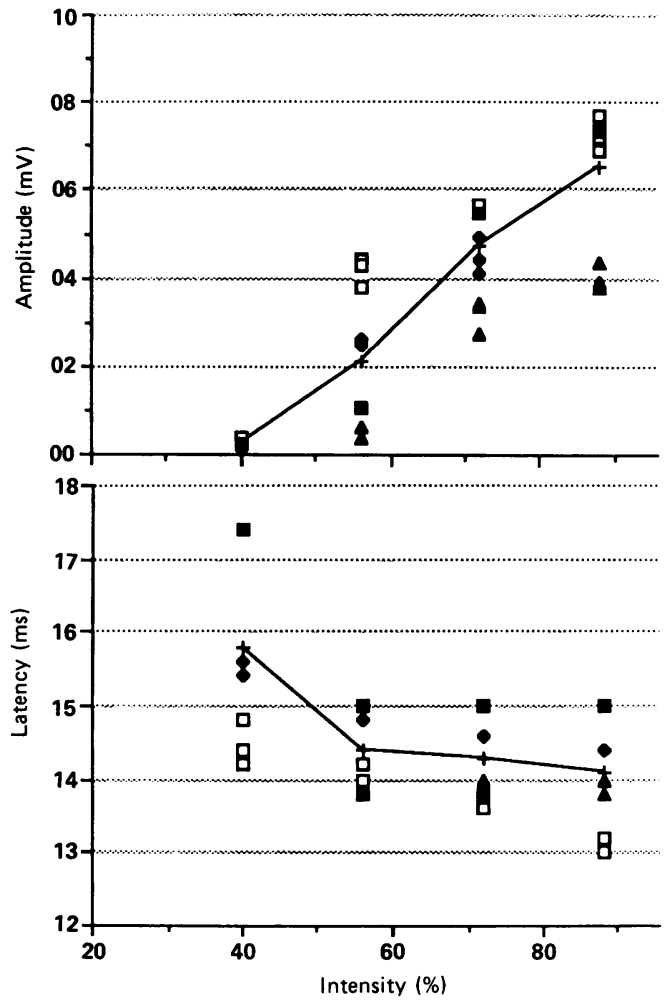

Figure 6 Amplitudes and latencies of CMAPs from the left ADM following anticlockwise magnetic stimulation over $C 7$ and increasing intensities. The symbols represent individual, and the solid line mean values (four subjects, three trials/intensity/subject).

shorter mean onset latencies of the responses from the left BICEPS by $0.218 \mathrm{~ms}$, whereas no significant latency difference was found from the ADM (figs 5 and 8, table 3).

Stimulation with increasing intensities resulted in a steady increase of amplitudes of CMAPs from both muscles. With one exception (fig 4, left BICEPS, anticlockwise), amplitudes did not saturate within the range of available stimulus intensities. This was true for all coil positions tested. Particularly in subjects of slender build, onset latencies of the CMAPs tended to shorten with increasing stimulus intensity and a significant latency decrease of about $1.4 \mathrm{~ms}$ was observed between an intensity of $40-60 \%$ (corresponding to a peak field of 0.9-1.4 Tesla in the centre of the coil). When the stimulus intensity was increased beyond $60 \%$, the latency shortened further only slightly.

Magnetic versus electrical root stimulation

Stimulation with the magnetic coil (C7 centred, anticlockwise current for the left side, and vice versa) provided on the average significantly smaller amplitudes of CMAPs from the ADM, and significantly greater amplitudes from the BICEPS than electrical stimulation (C7/T1 (-)) (tables 2 and 3). The mean latencies did not differ significantly between the two techniques (tables 1 and 3).

\section{Magnetic and electrical stimulation of the} brachial plexus at Erb's point

CMAPs from ADM and BICEPS were easily evoked with both electrical and magnetic 
Figure 7 Amplitudes and latencies of CMAPs from the left BICEPS following magnetic stimulation over C7 with anticlockwise current flow and increasing intensities. Individual (symbols) and mean values (solid line) in four subjects (three trials/ intensity/subject ).
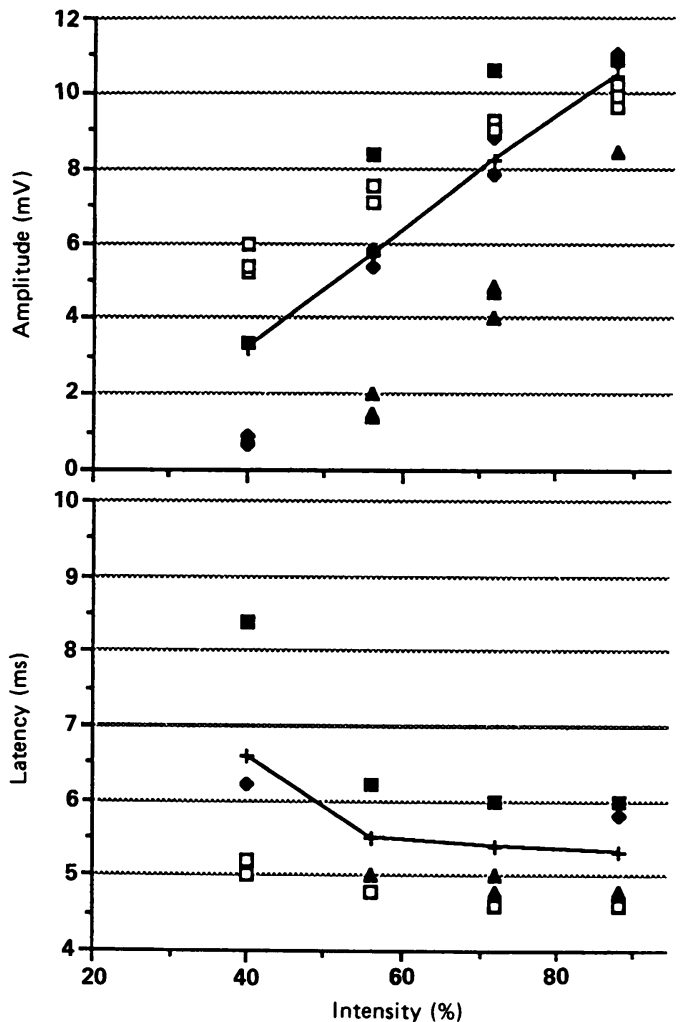

stimulation of the brachial plexus (fig 2), and the responses had a shape similar to those obtained from peripheral nerve stimulation. In contrast to results of stimulation over the spine, supramaximal responses could always be obtained. Stimulation with the magnetic coil provided on the average significantly smaller amplitudes and shorter onset latencies than electrical stimulation (tables 1, 2 and 4). From an estimated proximal nerve conduction velocity of $70 \mathrm{~m} / \mathrm{s}$ (table 1), an actual site of magnetic excitation about $3.5 \mathrm{~cm}$ distal to Erb's point could be calculated. The precise placement of the magnetic coil over Erb's point did not critically affect the latencies or amplitudes of the responses, provided that the coil was tightly put on the shoulder.

\section{MAGNETIC AND ELECTRICAL STIMULATION IN} PATIENTS

Cases 1 and 2 with cervical disc herniations had normal responses from the paretic muscles with either transcutaneous stimulation technique.

Case 4 with traumatic plexopathy had pathological side-to-side differences of onset laten-
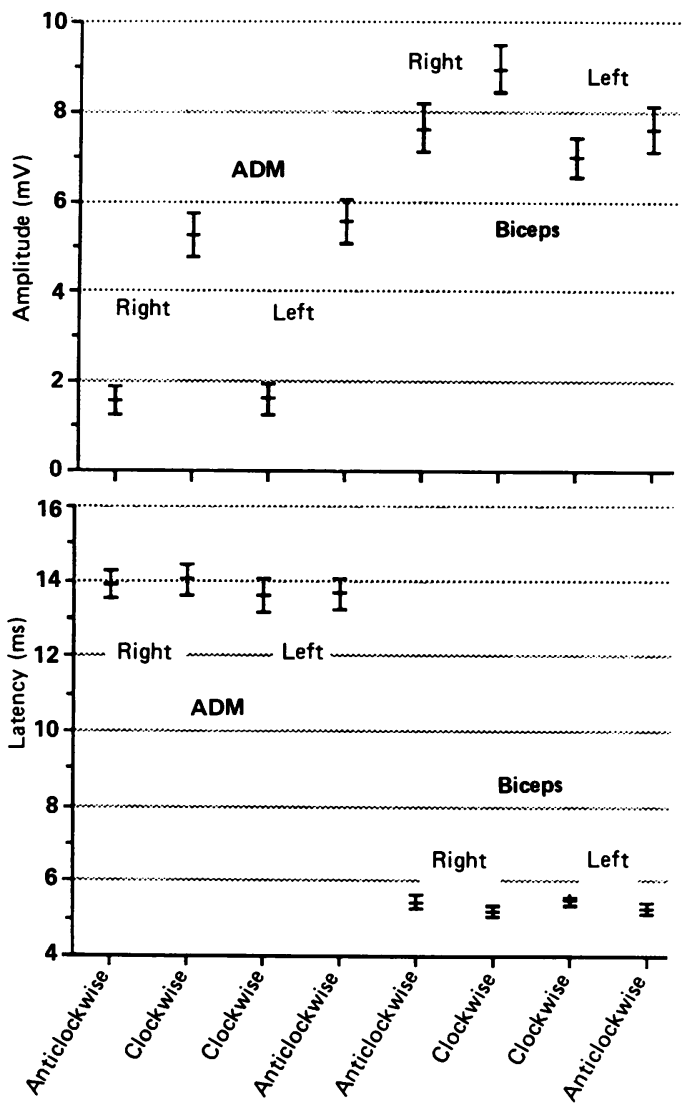

Figure 8 Amplitudes and latencies of CMAPs from left and right $A D M$ and BICEPS (mean values/standard error) following clockwise and anticlockwise magnetic stimulation over $C 7$ ( 22 subjects, 44 sides).

cies of CMAPs from the weak $A D M$ and BICEPS muscles.

Case 3 had normal preoperative responses from the clinically non-affected $A D M$ and BICEPS after transcutaneous electrical stimulation $\mathrm{C} 7 / \mathrm{T} 1(-)$ and over the brachial plexus. Latencies following transcutaneous electrical stimulation over the spinal column shortened when the stimulus intensity was unduly increased (fig 9 ). They were shorter by $0 \cdot 3-1 \cdot 4$ ms (ADM) and 0.9-2.2 ms (BICEPS) when compared to intraoperative root stimulation within the intervertebral foramen. The conduction times between direct intraforaminal C7 root and transcutaneous Erb's point stimulation were $2.3 \mathrm{~ms}(\mathrm{ADM})$ and $2.4 \mathrm{~ms}$ (BICEPS). From the distance of $16 \mathrm{~cm}$ measured between the spinous process $\mathrm{C} 7$ and Erb's point, proximal conduction velocities of $70 \mathrm{~m} / \mathrm{s}(A D M)$ and $67 \mathrm{~m} / \mathrm{s}$ (BICEPS) were calculated. The actual excitation site calculated

Table 4 Comparison of electrical and magnetic stimulation over Erb's point and recording from BICEPS and ADM ( $p$-value of the paired $t$ test)

\begin{tabular}{|c|c|c|c|c|c|c|c|}
\hline \multicolumn{3}{|c|}{ Stimulation and recording } & \multirow{2}{*}{\multicolumn{4}{|c|}{$\begin{array}{l}\text { Difference of the mean values, pooled data (1SD) } \\
A \text { minus } B\end{array}$}} & \multirow[b]{3}{*}{$\begin{array}{l}\text { Subject/ } \\
\text { sides }\end{array}$} \\
\hline \multirow{2}{*}{$\frac{A}{\text { Stimulation }}$} & \multicolumn{2}{|l|}{$B$} & & & & & \\
\hline & Stimulation & Recording & $\begin{array}{l}\text { Latency } \\
\text { (ms) }\end{array}$ & p-value & $\begin{array}{l}\text { Amplitudes } \\
(m V)\end{array}$ & p-value & \\
\hline $\begin{array}{l}\text { Electrical } \\
\text { Right } \\
\text { Left }\end{array}$ & $\begin{array}{l}\text { Magnetic } \\
\text { Anticlockwise } \\
\text { Clockwise }\end{array}$ & $\begin{array}{l}\text { BICEPS } \\
\text { Right } \\
\text { Left }\end{array}$ & $\begin{array}{l}+0.51 \\
(0.04)\end{array}$ & $\leqslant 0.0001$ & $\begin{array}{c}0.58 \\
(0 \cdot 20)\end{array}$ & $\leqslant 0.005$ & $22 / 44$ \\
\hline $\begin{array}{l}\text { Electrical } \\
\text { Right } \\
\text { Left }\end{array}$ & $\begin{array}{l}\text { Magnetic } \\
\text { Anticlockwise } \\
\text { Clockwise }\end{array}$ & $\begin{array}{l}\text { ADM } \\
\text { Right } \\
\text { Left }\end{array}$ & $\begin{array}{l}0.52 \\
(0.05)\end{array}$ & $\leqslant 0.0001$ & $\begin{array}{c}0.92 \\
(0 \cdot 21)\end{array}$ & $\leqslant 0.0001$ & $22 / 44$ \\
\hline
\end{tabular}


Figure 9 Latencies of $C M A P$ from left $A D M$ (rectangles) and BICEPS (triangles) during surgery. Intraforaminal electrical stimulation of the dural sleeve $C 7$ (C7 direct), transcutaneous electrical stimulation over $C 7 / T 1$ $(50-90 \%)$ (C7 transc), transcutaneous electrical stimulation at Erb's point (Erb).

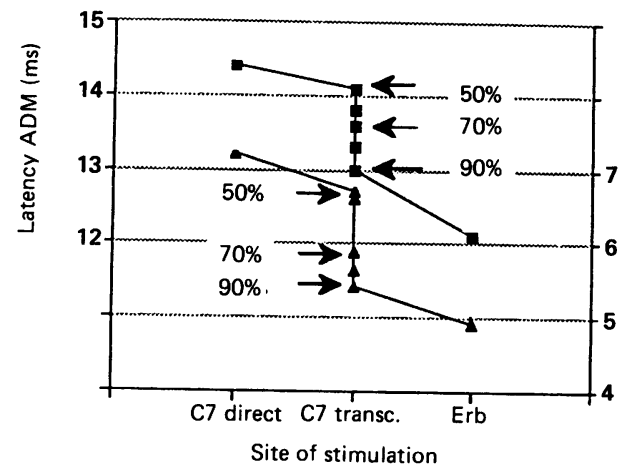

after transcutaneous root stimulation depended on the stimulus strength used: excitation occurred $2-10 \mathrm{~cm}$ distal to the intervertebral foramen, and 6-14 cm proximal to Erb's point.

\section{Discussion}

Both high voltage electrical and magnetic stimulation are capable of exciting the cervical motor roots transcutaneously, allowing direct electroneurographic assessment of the proximal segment of the brachial plexus. While the local discomfort caused by the electrical and magnetic root stimulation was similar and well tolerated, magnetic stimulation of the brachial plexus was clearly preferred to the sharp electrical stimulus over Erb's point. Magnetic stimulation may therefore render plexus stimulation more acceptable in clinical praxis.

With the methods described and particularly for stimulation over the spine, the stimulation electrode or coil is relatively far away from the excited nerve fibres. Therefore, considerable spread of the stimulating currents in the surrounding tissue must be assumed when the stimulus is strong enough to reach sufficient depths. Transcutaneous stimulation of deep neural structures depends largely on the strength and orientation of the applied stimulus, ${ }^{5}$ the remoteness of the nerve fibres, and on the specific impedances of the surrounding tissue. Since the conductivity of the tissue at the level of the cervical column is far from homogeneous, the density and direction of the stimulating current is difficult to predict. ${ }^{3}$ Using a sophisticated F-wave technique and direct needle stimulation, Mills and Murray ${ }^{3}$ have shown that with high voltage electrical stimulation applied over the back of the neck and recording from ADM, excitation of the cervical motor roots reaches to the exit foramen or even further distally. In view of a practical application of the techniques, the crucial questions are, whether the actual site of excitation of the nerve fibres can be appropriately determined, and whether and how it is influenced by the stimulation technique.

For electrical cervical root stimulation we have shown previously that longitudinal median positioning $\mathrm{C} 7 / \mathrm{T} 1$ (-) of the stimulating electrodes and an interelectrode distance of $6 \mathrm{~cm}$ are optimal, ${ }^{5}$ because the tendency of the stimulus to spread distally was less pronounced than with a transverse or paramedian electrode position, or than with a greater interelectrode distance. ${ }^{5}$ Nevertheless, as described by others using this technique, ${ }^{17}$ we sometimes observed a latency jump of up to $1 \mathrm{~ms}$ (fig 3), equivalent to a distance of about $7 \mathrm{~cm}$, when the electrical stimulus was enhanced to a far more supramaximal level. This awkward "reaching down phenomenon" of very strong electrical stimuli was unpredictable and varied in extent from subject to subject. It could be avoided though, when the stimulus intensity was not raised above a magnitude sufficient to yield a just maximal amplitude. For exciting the ADM and BICEPS simultaneously on both sides, we found it best to place the cathode over the C7/ $\mathrm{T} 1$ interspace and the anode $6 \mathrm{~cm}$ cranially. ${ }^{18}$ When reversing the polarity, amplitudes of CMAP from the BICEPS were slightly raised at the expense of a much diminished ADM response (table 3). At the same time, onset latencies of the BICEPS responses increased on the average by $0.6 \mathrm{~ms}$, while those of the ADM remained unchanged (table 3 ).

For magnetic stimulation of cervical motor roots, a fairly large coil of $8 \mathrm{~cm}$ mean diameter and an ample inner space that allowed tight placement around the $\mathrm{C} 7$ spinous process proved optimal for exciting the ADM and BICEPS simultaneously (figs 5 and 8). Placing the coil over the spinous process $\mathrm{C} 6$ or C5 rather than $\mathrm{C} 7$ resulted in a moderately augmented response from the ADM, and a much diminished response from the BICEPS in most subjects while, with the coil over the process $\mathrm{T} 1$, the responses from both muscles were diminished (fig 4). Moving the coil along the midline over the spinous processes affected the responses from the two muscles, suggesting that the main stimulating effect occurred beneath the horizontal segments of the coil. The sense of the inducing current affected primarily the amplitudes of muscle responses, a finding which has already been described by Ugawa et al. ${ }^{19}$ With the coil over C7 and the current anticlockwise as viewed from behind, the responses from the left side of the ADM were greater than with the current clockwise (figs 5 and 8). The influence of the current sense was less important for the BICEPS responses and for the latencies of either muscles (fig 8). When raising the stimulus, amplitudes saturated only exceptionally within available intensities while onset latency shortened notably. Only in the top range of the stimulus intensity did the latencies remain fairly stable (figs 5, 6 and 7). Therefore, in contrast to electrical root stimuli (fig 3), strong magnetic stimuli yield more reliable latencies than weak ones.

When magnetic and electrical root stimulation over the cervical column were compared using the techniques already mentioned, electrical stimulation yielded smaller amplitudes in the BICEPS and greater amplitudes in the ADM (table 3). Since onset latencies after electrical and magnetic stimulation did not differ statistically, the actual site of stimulation for the fastest conducting root fibres are assumed to be approximately the same.

In contrast, magnetic stimulation of the brachial plexus over Erb's point yielded greater amplitudes and an average of $0.5 \mathrm{~ms}$ shorter 
onset latencies than electrical stimuli but with similar standard deviations. From this, a fairly constant actual site of excitation from magnetic stimulation of about $3.5 \mathrm{~cm}$ distal to Erb's point can be reckoned, that is, approximately where the plexus crosses the clavicle.

Our intraoperative stimulation experiment shows that it is not possible to confine a transcutaneous stimulus to the very proximal segment of the motor root just at the cord or at least within the spinal column, which would have been most helpful for clinical application. Hence, excitation of the fastest motor nerve fibres occurs outside the intervertebral foramen as has already been suspected. ${ }^{351719}$ This assumption is also supported by our studies in patients with disc herniations with compressed cervical roots, where transcutaneous electrical and magnetic stimulation provided normal latencies of responses from weak ADM or BICEPS, suggesting that excitation occurred distal to the compressed root segment. Therefore, lesions within the intraspinal segment of the roots remain inaccessible to direct neurography. As the total number of motor axons supplying a target muscle can often not be stimulated, amplitudes are of limited diagnostic value in motor root stimulation and particularly so with magnetic stimulation.

Note added in proof:

The current direction in the coil was defined according to the flux of negativity.

We thank Professor H J Reulen for allowing us to study his patients. This study was supported by the Swiss National Science Foundation (Grants-Nr. 3.852-1.86; 3.884-1.86), the Wander Stiftung, and Swiss MS Society.
1 Merton PA, Morton HB. Electrical stimulation of human motor and visual cortex through the scalp. J Physiol (London) 1980;305:9P-10P.

2 Marsden CD, Merton PA, Morton HB. Percutaneous stimulation of spinal cord and brain: Pyramidal tract conduction velocities in man. J Physiol (London) 1982; 328:6P.

3 Mills KR, Murray NMF. Electrical stimulation over the human vertebral column: which neural elements are human vertebral column: which neural elem

4 Ludolph AC, Spille M, Masur H. Methodik und Normalwerte für die Ableitung von evozierten Muskelpotentialen nach Stimulation über den motorischen Wurzein. Z EEGEMG 1988;19:71-4

5 Schmid UD, Hess ChW, Ludin HP. Percutaneous electrical stimulation of the cervical motor roots: Methodology and normal values. $Z$ EEG-EMG 1989;20:39-49.

6 Barker AT, Jalinous R, Freeston IL. Non-invasive magnetic stimulation of human motor cortex. Lancet 1985;ii: 1106-7.

7 Hess CW, Mills KR, Murray NMF. Responses in small hand muscles from magnetic stimulation of the human hand muscles from magnetic stimulation of

8 Santamaria J, King PJL, Cros D, Chiappa KH. Cervical magnetic stimulation: Root or spinal nerves? Neurology 1988;38(suppl): 199 .

9 Spire JP, Maselli RA, Soliven B, et al. Magnetic stimulation of the human peripheral nervous system. Muscle Nerve 1987;10:643A.

10 Barker AT, Freeston IL, Jalinous R, Jarratt JA. Magnetic stimulation of the human brain and peripheral nervous system: An introduction and the results of an initial clinical evaluation. Neurosurg 1987;20:100-9.

11 Schmid UD, Walker G, Hess CW. A Comparison of Magnetic and Electrical Cervical Motor Root Stimulation Techniques. EEG Clin Neurophysiol 1990;75(5):69.

12 Polson MJR, Barker AT, Freeston IL. Stimulation of nerve trunks with time varying magnetic fields. Med Biol Eng trunks with time varying

13 Dressler D, Benecke R, Meyer BU, Conrad B. The role of magnetic stimulation for investigation of the peripheral nervous system. $Z$ EEG-EMG 1988;19:260-3

14 Bickford RG, Guidi M, Fortesque P, Swenson M. Magnetic stimulation of human peripheral nerve and brain: Response enhancement by combined magnetoelectrical technique. Neurosurg 1987;20:110-5.

15 Mills KR, Murray NMF. Proximal slowing and conduction block in acute and chronic demyelinating neuropathy. $J$ Neurol Neurosurg Psychiatry 1986;49:476

16 Ludolph AC, Spille M, Masur H, Elger CE. Results in the peripheral motor system after stimulation of motor roots: polyradiculitis, amyotrophic lateral sclerosis, polyneuropothy. Z EEG-EMG 1988;19:255-9.

17 Plassman BL, Gandevia SC. High voltage stimulation over the human spinal cord: Sources of latency variation. the human spinal cord: Sources of latency
$J$ Neurol Neurosurg Psychiatry 1989;52:213-7.

18 Kendall HO, Kendall FP, Wadsworth GE. Nerve and muscle charts. Muscles, testing and function. Baltimore: Williams and Wilkins, 1971:38-50.

19 Ugawa Y, Rothwell JL, Day BL, Thompson PD, Marsden CD. Magnetic stimulation over the spinal enlargements. J Neurol Neurosurg Psychiatry 1989;52:1025-32. 